\title{
REFLEXÕES CRÍTICAS QUANTO AS LIMITAÇÕES DO TEXTO DAS NORMAS BRASILEIRAS DE DESEMPENHO NBR 15220-3 E NBR 15575
}

\author{
A. J. BOGO \\ Universidade Regional de Blumenau \\ bogo.amilcar@gmail.com
}

Artigo submetido em 04/2016 e aceito em 09/2016

DOI: 10.15628/holos.2016.4389

\section{RESUMO}

Este artigo apresenta uma série de reflexões críticas quanto aos textos das Normas NBR 15220 - Desempenho térmico de edificações - Parte 3: Zoneamento Bioclimático Brasileiro e Diretrizes Construtivas para Habitações Unifamiliares de Interesse Social, e NBR 15575 - Edifícios habitacionais - Desempenho - Parte 4 Vedações Verticais e Parte 5 Coberturas (Avaliação simplificada do desempenho térmico). As críticas do primeiro texto da Norma referem-se as cidades localizadas em clima subtropical e do segundo texto a todas 8 zonas bioclimáticas do Brasil. No que se refere a NBR 15220-3, esta não contempla algumas diretrizes construtivas e estratégias de condicionamento térmico passivo necessárias para cidades com clima subtropical. Já para a NBR 15575, identificou-se também a ausência de algumas diretrizes, como fator solar máximo de aberturas e capacidade térmica de coberturas.

PALAVRAS-CHAVE: Eco-compósito, Poliuretano de Mamona, Rejeito de Madeira, Propriedades Térmicas.

\section{CRITICAL REVIEW OF LIMITATIONS OF THE BRASILIAN NBR 15220-3 AND NBR 15575 STANDARDS}

\begin{abstract}
This paper presents a series of critical review about the NBR 15220 Standard - Thermal performance of buildings - Part 3: Zoning Brazilian Bioclimatic and Constructive Guidelines for Single-family Dwellings Social Interest, and NBR 15575 Standard - Residential buildings Performance - Part 4 Walls and Part 5 Roofings. The critical review of the first text of the standard refers cities located in the subtropical climate and the second text of
\end{abstract}

8 to all bioclimatic zones of Brazil. As regards the NBR 15220-3 does not include some constructive guidelines and strategies needed to passive thermal conditioning cities with subtropical climate. Have to NBR 15575, also identified the absence of some guidelines, such as solar maximum factor of openings and thermal capacity of roofings.

KEYWORDS: Standardization, Thermal performance, Bioclimatic zones, Buildings guidelines. 


\section{APRESENTAÇÃO}

Os estudos iniciais visando uma norma brasileira de desempenho térmico de edificações ocorreram no final da década de 1980, com a criação do Grupo de Conforto Ambiental e Eficiência Energética da ANTAC em 1988, segundo Roriz, Ghisi e Lamberts (1999). Estes autores informam ainda que em 1991 foi realizado o 1 Encontro Nacional Sobre Normalização Quanto ao Uso Racional de Energia e ao Conforto Térmico em Edificações e depois houveram muitas ações visando a definição de Normas Brasileiras, com a definição de propostas com diferentes abrangências e pressupostos

Depois, os mesmos autores citam que visando unificar e oficializar este processo foi criada uma Comissão de Estudos sobre Desempenho Térmico e Eficiência Energética de Edificações, vinculada ao Comitê Brasileiro de Construção Civil da Associação Brasileira de Norma Técnicas (ABNT).

Mais tarde em 1998, estes autores informam que houveram ações visando compatibilizar os diferentes textos em proposição para a norma de desempenho térmico de edificações.

Atualmente, na área de desempenho térmico de edificações existem no Brasil as normas NBR 15220, ABNT (2005) com 5 partes e NBR 15575, ABNT (2013) com 6 partes, suprindo inicialmente uma lacuna existente no país quanto a questão da normalização do desempenho térmico de edificações, já presente em diversos países.

\section{ANÁLISE CRÍTICA DAS NORMAS}

Após a publicação da primeira norma em 2005 (NBR 15220), diversos autores apresentaram propostas de aperfeiçoamento, melhorias, adaptações, assim como já vêm ocorrendo no caso da NBR 15575 publicada em 2013, num processo de contínua melhoria, como no caso do trabalho de Sorgato, Melo e Lamberts (2014) sobre esta última norma, Oliveira, Souza e Silva (2013) sobre as duas normas, Brito et al (2012) e D'ell Santo, Alvarez e Nico-Rodrigues (2013) também sobre a NBR 15575 , dentre os mais recentes.

O artigo aqui apresentado contribui com uma série de reflexões críticas quanto aos textos das Normas antes citadas, no sentido de identificar limitações a serem supridas em estudos posteriores.

Segundo a NBR 15220-3, ABNT (2005), Norma Brasileira sobre Desempenho Térmico de Edificações, Parte 3 - Zoneamento Bioclimático Brasileiro e Diretrizes Construtivas para Habitações Unifamiliares de Interesse Social, existem no país os tipos bioclimáticos $1,2,3,4,5,6,7,8$, identificados segundo características próprias e adiante apresentados na Figura 1: 


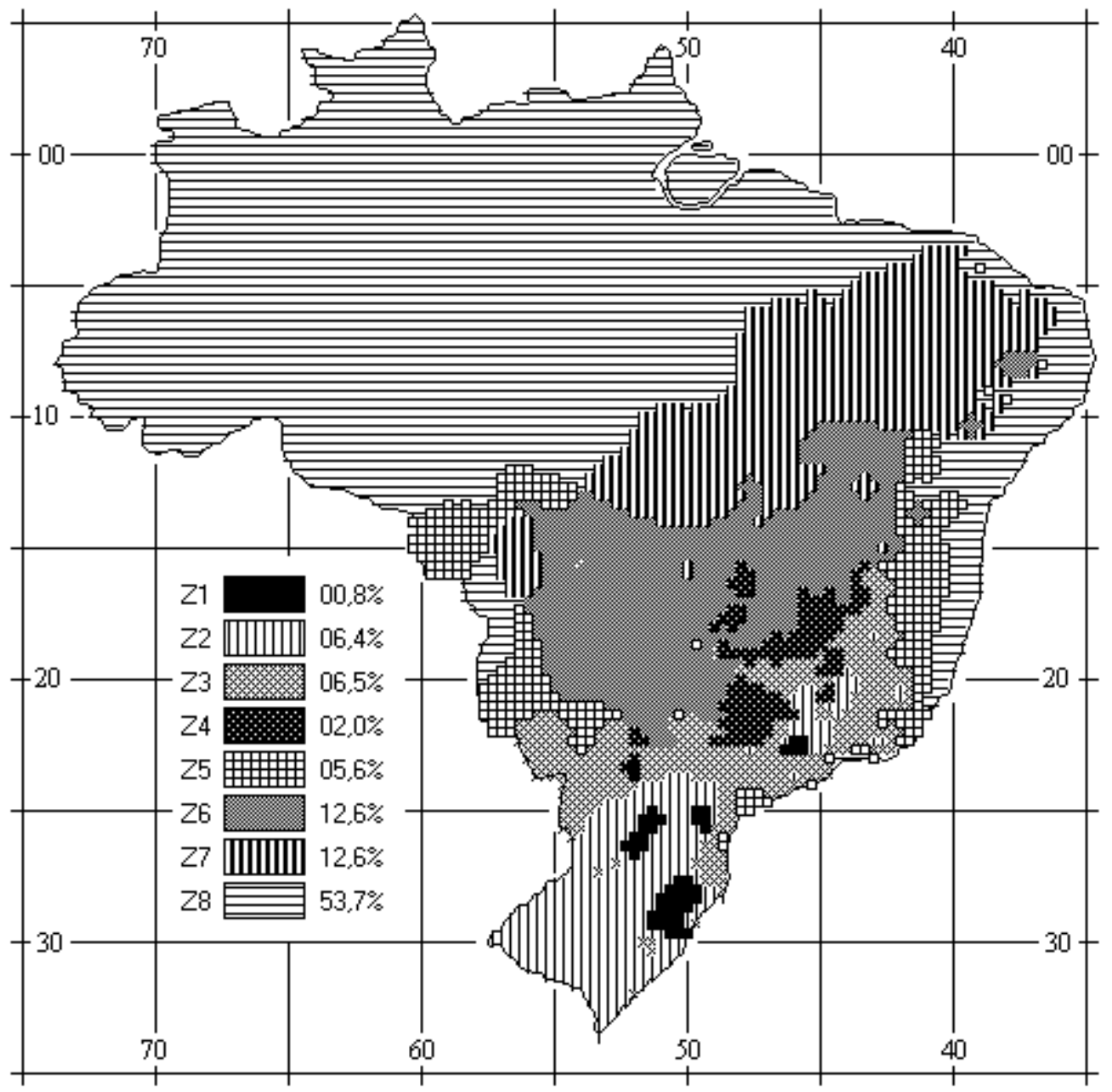

Figura 1 - Zoneamento bioclimático brasileiro. Fonte: ABNT, 2005

De acordo com Bogo (2008), a norma brasileira NBR 15220-3 aprovada em 2005, em parte tem limitações por não contemplar algumas diretrizes construtivas e estratégias de condicionamento térmico passivo para cidades com clima subtropical, na sua maioria localizadas no Sul do Brasil.

2.1 Limitações identificadas na norma NBR 15220-3: diretrizes construtivas e estratégias de condicionamento térmico passivo

Analisando-se as zonas bioclimáticas existentes no texto da norma, identificou-se que para a zona 3 e respectivas cidades que fazem parte, não existe a recomendação de sombrear as aberturas no verão, conforme abaixo identificado:

Zona Bioclimática 3:

Verão - Ventilação cruzada;

Inverno - Aquecimento solar; inércia térmica; (condicionamento passivo insuficiente durante período mais frio do ano);

Em parte isto se deve ao fato de que na formulação do zoneamento bioclimático brasileiro, baseado no Método de Givoni (GIVONI, 1992), não existe a estratégia de controle solar, conforme adiante identificado. 
As zonas da carta de Givoni adaptada, adotadas na formulação da norma, correspondem às estratégias adiante apresentadas na Figura 2:

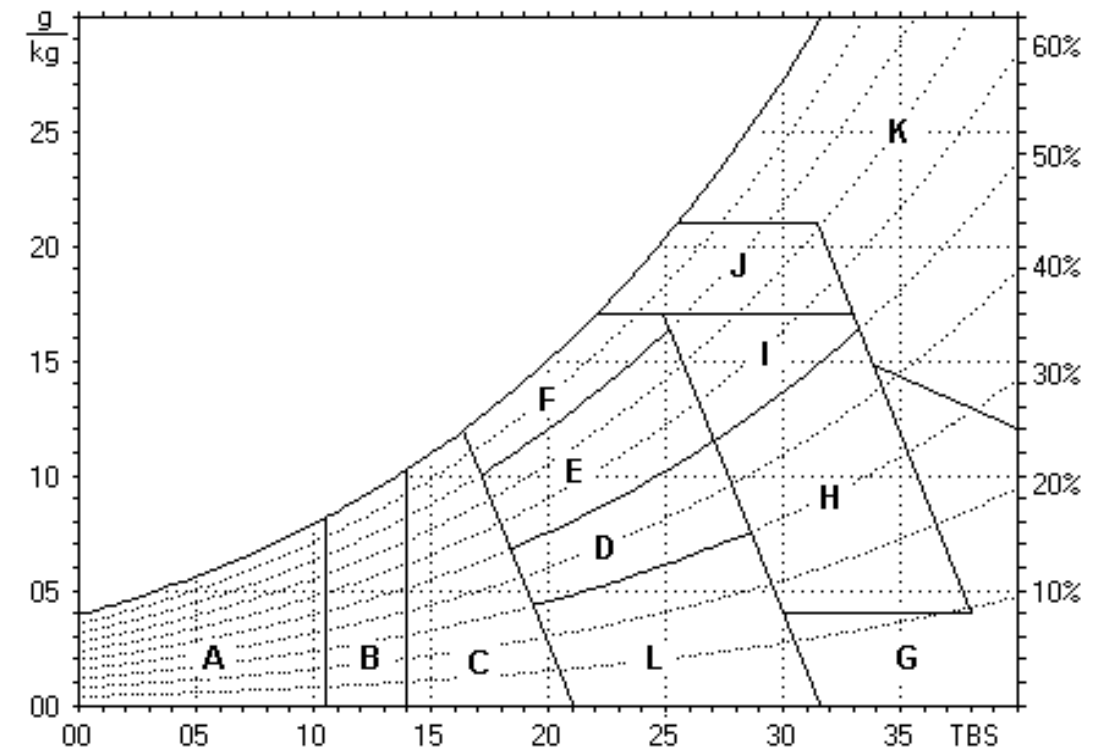

Figura 2 - Estratégias de condicionamento térmico recomendadas no zoneamento bioclimático brasileiro - Fonte: ABNT, 2005

Legenda:

As áreas da carta psicrométrica acima, identificadas com as letras A até K, correspondem as estratégias de condicionamento térmico recomendadas adiante especificadas na Tabela 1:

Tabela 1: Estratégias de condicionamento térmico recomendadas segundo Givoni

\begin{tabular}{|ll}
\hline A - Zona de aquecimento artificial (calefação) & F - Zona de desumidificação (renovação do ar) \\
B - Zona de aquecimento solar da edificação & $\mathrm{G}+\mathrm{H}$ - Zona de resfriamento evaporativo \\
C - Zona de massa térmica para aquecimento & $\mathrm{H}+\mathrm{I}$ - Zona de massa térmica de refrigeração \\
D - Zona de Conforto Térmico (baixa umidade) & $\mathrm{I}+\mathrm{J}$ - Zona de ventilação \\
E-Zona de Conforto Térmico & $\mathrm{K}$ - Zona de refrigeração artificial \\
& $\mathrm{L}-$ Zona de umidificação do ar
\end{tabular}

* Ausência da estratégia de controle solar.

O quesito controle da insolação direta excessiva não é contemplado nas estratégias de condicionamento térmico recomendadas visando melhoria das condições internas. Neste método adotado, sobre a carta psicrométrica são definidas zonas, uma de conforto e outras de estratégias de condicionamento térmico visando o conforto. A ausência de estratégia de controle solar é uma situação inadequada, pois uma das principais estratégias para melhoria do desempenho térmico das edificações e que afeta o conforto térmico dos ocupantes, é o controle da insolação direta excessiva, tanto para as cidades de clima com maior rigor climático de calor, assim como para as demais no período de verão.

Neste sentido Bruand (1999) identifica quatro preocupações que o arquiteto necessita ter quanto ao projeto de arquitetura no clima brasileiro: 1) evitar o excesso de insolação e luminosidade provenientes de uma insolação intensa; 2) circulação do ar (ventilação); 3) proteção contra a chuva; 4) conservação dos materiais. 
Ao mesmo tempo, a estratégia de controle solar (sombrear as aberturas) é apresentada nas zonas bioclimáticas 4, 5, 6, 7 e 8, mesmo não existindo no Método de Givoni esta estratégia.

Adotando-se outro método de avaliação climática, o Método das Tabelas de Mahoney (MAHONEY, 1971) implementado no Programa ARQUITROP (RORIZ e BASSO, 1995), identificou-se que o rigor térmico de calor existe na seguinte quantidade do ano (dia e noite, de janeiro a dezembro), para algumas cidades identificadas para a zona bioclimática 3 na Tabela 2 adiante:

Tabela 2: Rigor térmico de calor para algumas cidades da zona bioclimática 3

\begin{tabular}{|c|c|c|}
\hline $\begin{array}{l}\text { Santa Catarina: } \\
\text { Florianópolis: } 6 \text { períodos; } \\
\text { Camboriú: } 6 \text { períodos; } \\
\text { Blumenau: } 6 \text { períodos; } \\
\text { São Paulo: } \\
\text { São Paulo: } 4 \text { períodos; } \\
\text { Campinas: } 5 \text { períodos; } \\
\text { Sorocaba: } 5 \text { períodos; } \\
\text { Ubatuba: } 6 \text { períodos; }\end{array}$ & $\begin{array}{l}\text { Paraná: } \\
\text { Paranaguá: } 6 \text { períodos; } \\
\text { Rio Grande do Sul: } \\
\text { Iraí: } 6 \text { períodos; } \\
\text { Porto Alegre: } 4 \text { períodos; } \\
\text { Rio Grande: } 5 \text { períodos; }\end{array}$ & $\begin{array}{l}\text { Rio de Janeiro: } \\
\text { Rezende: } 8 \text { períodos; } \\
\text { Vassouras: } 4 \text { períodos. } \\
\text { Minas Gerais: } \\
\text { Belo Horizonte: } 3 \text { períodos; } \\
\text { Lavras: } 8 \text { períodos. }\end{array}$ \\
\hline
\end{tabular}

Cabe destacar novamente que uma das principais estratégias de condicionamento térmico adotadas para minimizar os problemas de calor, é a de proteger as aberturas, ou seja, o controle da insolação direta excessiva.

Outra limitação que foi identificada se deve ao fato de serem classificadas numa mesma zona bioclimática cidades com altitudes bastante diversas, como Camboriú no litoral de Santa Catarina com $8 \mathrm{~m}$ de altitude e Chapecó à $400 \mathrm{~km}$ do litoral em direção ao oeste com $679 \mathrm{~m}$ de altitude, ambas enquadradas na zona bioclimática 3, (BOGO e PEREIRA, 2003). Outra classificação questionável é a de Petrópolis - RJ com $895 \mathrm{~m}$ de altitude (2 períodos de calor) e Rezende com 439 $\mathrm{m}$ de altitude ( 8 períodos de calor), ambas também na zona bioclimática 3 .

A classificação de cidades numa mesma zona bioclimática com altitude e rigor térmico díspares, em parte é devido a falta de refinamento do zoneamento bioclimático, pela falta de dados climatológicos ou sua consideração para um maior número de cidades do território brasileiro, situação esta que a nova proposta de zoneamento bioclimático pretende minimizar.

O parâmetro recomendado de transmitância térmica para coberturas, categorizado como leve isolada ( $U$ menor ou igual a $2 \mathrm{~W} / \mathrm{m}^{2} \mathrm{~K}$ ) para algumas zonas bioclimáticas, é um valor alto, pois utilizando-se isolamento térmico numa cobertura, o valor de $U$ reduz a cerca de 1,18 a 0,62 W/m² $\mathrm{K}$, conforme apresentado no anexo $\mathrm{D}$ informativo com avaliação da transmitância térmica $U$, da capacidade térmica $\mathrm{Ct}$, e do atraso térmico de coberturas com uso de isolamento do tipo radiativo (lâmina de alumínio) e do tipo resistivo (lã de vidro).

Já para as zonas bioclimáticas 1 e 2, são apresentados adiante nas Tabelas 1 até 8 as diretrizes construtivas e as estratégias de condicionamento térmico passivo do texto da norma:

Zona Bioclimática 1:

Tabela 3: Aberturas para ventilação e sombreamento das aberturas para a Zona Bioclimática 1

\begin{tabular}{|l|l|}
\hline Aberturas para ventilação & Sombreamento das aberturas \\
\hline Médias & Permitir sol durante o período frio \\
\hline
\end{tabular}

Tabela 4: Tipos de vedações externas para a Zona Bioclimática 1 


\begin{tabular}{|l|}
\hline Vedações externas \\
\hline Paredes: leve \\
\hline Coberturas: leve isolada \\
\hline
\end{tabular}

Tabela 5: estratégias de condicionamento térmico passivo para a zona bioclimática 1

\begin{tabular}{|l|l|}
\hline Estação & Estratégias de condicionamento térmico passivo \\
\hline \multirow{3}{*}{ Inverno } & $\begin{array}{l}\text { Aquecimento solar da edificação } \\
\text { Vedações internas pesadas (inércia térmica) } \\
* \text { O condicionamento passivo será insuficiente durante o período mais frio do } \\
\text { ano }\end{array}$ \\
\hline
\end{tabular}

Zona Bioclimática 2:

Tabela 6: Aberturas para ventilação e sombreamento das aberturas para a Zona Bioclimática 2

\begin{tabular}{|l|l|}
\hline Aberturas para ventilação & Sombreamento das aberturas \\
\hline Médias & Permitir sol durante o período frio \\
\hline
\end{tabular}

Tabela 7: Tipos de vedações externas para a Zona Bioclimática 2

\begin{tabular}{|l|}
\hline \multicolumn{1}{|c|}{ Vedações externas } \\
\hline Paredes: leve \\
\hline Coberturas: leve isolada \\
\hline
\end{tabular}

Tabela 8: Tipos de vedações externas para a Zona Bioclimática 2

\begin{tabular}{|l|l|}
\hline Estação & Estratégias de condicionamento térmico passivo \\
\hline Verão & Ventilação cruzada \\
\hline \multirow{3}{*}{ Inverno } & $\begin{array}{l}\text { Aquecimento solar da edificação } \\
\text { Vedações internas pesadas (inércia térmica) } \\
\text { *O condicionamento passivo será insuficiente durante o período mais frio do } \\
\text { ano }\end{array}$ \\
\hline
\end{tabular}

Assim como na zona 3, inexiste para o verão nas zonas bioclimáticas 1 e 2 a estratégia de sombrear as aberturas no verão a partir de elementos de controle solar móveis (com flexibilidade segundo as necessidades de cada estação do ano), situação esta também desejável nos períodos de calor, mesmo em se tratando de tipos climáticos representativos de cidades com maior rigor térmico de frio, como ocorre nestas 2 zonas.

\subsection{Limitações identificadas na norma NBR 15575}

Analisando-se os critérios de desempenho térmico (transmitância térmica e capacidade térmica) recomendados para as zonas bioclimáticas 1 até 8 segundo a Norma NBR 15575, identificamos adiante nas Tabelas 9 e 10 as características para coberturas e paredes externas:

\subsubsection{Avaliação simplificada do desempenho térmico: coberturas}

Tabela 9: Transmitância térmica mínima para coberturas segundo a NBR 15575

\begin{tabular}{|c|c|c|c|c|}
\hline \multicolumn{3}{|c|}{ Coberturas } & \multicolumn{1}{c|}{$\begin{array}{l}\text { Transmitância térmica - (U) W/m².K } \\
\text { Desempenho Mínimo }\end{array}$} \\
\hline Zonas 1 e 2 & Zonas 3 a 6 & Zonas 7 e 8* \\
\hline \multirow{2}{*}{$\leq 2,30$} & $\alpha \leq 0,6$ & $\alpha>0,6$ & $\alpha \leq 0,4$ & $\alpha>0,4$ \\
\hline & $\leq 2,30$ & $\leq 1,50$ & $\leq 2,30 \mathrm{FV}$ & $\leq 1,50 \mathrm{FV}$ \\
\hline
\end{tabular}


Onde $\alpha$ é absortância à radiação solar da superfície externa da cobertura e FV é o fator de ventilação estabelecido na ABNT NBR 15220-2, em função das dimensões das aberturas de ventilação nos beirais.

* Na zona bioclimática 8 considera-se atendido o critério para coberturas em telhas cerâmicas, mesmo sem a presença de forro.

No texto desta Norma, não existem exigências quanto a Capacidade Térmica para coberturas, situação esta inadequada, pois as mesmas não proporcionam um retardo térmico mínimo, que contribui para a redução das temperaturas internas do ar nos ambientes abaixo das mesmas.

Os valores de transmitância térmica minimamente exigidos são altos, identificando coberturas sem isolamento térmico, não desejáveis para aquelas zonas bioclimáticas localizadas em regiões de rigor térmico de calor na quase totalidade do ano.

\subsubsection{Avaliação simplificada do desempenho térmico: paredes externas}

Tabela 10: Transmitância térmica para paredes externas segundo a NBR 15575

\begin{tabular}{|l|l|l|}
\hline \multicolumn{3}{|c|}{ Paredes externas - Transmitância térmica - $(\mathrm{U}) \mathrm{W} / \mathrm{m}^{2} . \mathrm{K}$} \\
\hline \multirow{3}{*}{ Zonas 1 e 2} & \multicolumn{2}{c|}{ Zonas 3 a 8} \\
\hline \multirow{2}{*}{$\leq 2,50$} & $\alpha \leq 0,6$ & $\alpha>0,6$ \\
\cline { 2 - 3 } & $\leq 3,70$ & $\leq 2,50$ \\
\hline
\end{tabular}

Onde $\alpha$ é absortância à radiação solar da superfície externa da parede

Na Tabela 11 adiante é apresentada a capacidade térmica para paredes externas segundo a NBR 15575. Esta norma não apresenta recomendações para coberturas no que se refere a capacidade térmica.

Tabela 11: Capacidade térmica para paredes externas segundo a NBR 15575

\begin{tabular}{|c|c|}
\hline Paredes externas & - Capacidade Térmica $\mathrm{Ct}$ \\
\hline Zonas 8 & $\mathrm{~kJ} / \mathrm{m}^{2} . \mathrm{K}$ \\
\hline Sem requisito & Zonas 1, a 7 \\
\hline
\end{tabular}

Outra questão que merece ser melhor abordada e destacada refere-se ao Ganho de Calor Solar através de elementos opacos (paredes, coberturas), comparativamente aos elementos transparentes (envidraçados: janelas e porta-janelas). Uma estimativa do ganho de calor solar de $1 \mathrm{~m}^{2}$ de cobertura (telha cerâmica + ático + laje pré-moldada) comparado com $1 \mathrm{~m}^{2}$ de uma janela comum (com transmitância à radiação solar de 0,85: vidro comum) permite a clara compreensão da necessidade de soluções arquitetônicas para as janelas, que dependendo da latitude e clima da cidade, da época do ano e da orientação solar, caracterizam-se como o local de maior entrada de calor solar para o interior da edificação, ao lado da cobertura.

Na Tabela 12 adiante é apresentado o desempenho mínimo de ventilação para ambientes de permanência prolongada. 
Tabela 12: Aberturas para ventilação de ambientes de permanência prolongada: desempenho mínimo

\begin{tabular}{|c|l|}
\hline \multicolumn{2}{|c|}{ Aberturas para ventilação (A) } \\
\hline Zonas 1 a 7 - Aberturas médias & Zona 8 - Aberturas grandes \\
\hline $\mathrm{A} \geq 7 \%$ da área de piso & $\begin{array}{l}\mathrm{A} \geq 12 \% \text { da área de piso - Região Norte do Brasil } \\
\mathrm{A} \geq 8 \% \text { da área de piso - Região Nordeste e } \\
\text { Sudeste do Brasil }\end{array}$ \\
\hline
\end{tabular}

Nota: Nas zonas de 1 a 6 as áreas de ventilação devem ser passíveis de serem vedadas durante o período de frio.

Neste quesito, além da área mínima de ventilação, deveria ser exigido a ventilação cruzada, em especial para ambientes do tipo banheiros, lavabos, cozinhas, entre outros, geradores de gases, odores, vapor d'água.

\section{CONCLUSÕES}

O Método de Givoni adotado na definição da zona de conforto (e demais zonas estratégias de condicionamento térmico) para a norma visando a definição do zoneamento bioclimático não contempla o quesito controle da insolação direta, apresentando uma falha importante quanto à definição das estratégias de condicionamento térmico recomendadas. O controle solar nas aberturas e na edificação como um todo, é um dos principais pontos para se obter melhorias no desempenho térmico da edificação, com melhorias no conforto térmico interior para os períodos de calor.

O Método das tabelas de Mahoney com diagnóstico do rigor climático para o clima local das cidades analisadas, assim como a definição de recomendações de projeto em nível de implantação da edificação no terreno, espaçamento, movimento do ar, tamanho e posição das aberturas, proteção das aberturas, diretrizes construtivas para paredes e coberturas, consiste num método de apoio ao desenvolvimento do projeto de arquitetura. Este método citado é de grande valia, pois trabalha claramente com as varáveis de concepção da arquitetura, sendo de fácil aplicação a partir de dados simplificados do clima local, podendo ser incorporado nos estudos de revisão do zoneamento bioclimático brasileiro.

As limitações da Norma NBR 15220-3 concentram-se na ausência da exigência do controle do excesso de Sol nos ambientes para os períodos de calor, também necessárias para as zonas bioclimáticas 1, 2 e 3, assim como incoerências de mesma classificação bioclimática para cidades com situações geográficas distintas, e parâmetros de transmitância térmica elevados para as coberturas.

A Norma NBR 15575 de desempenho, ao invés de aprimorar as recomendações sobre desempenho térmico, é ainda mais limitada, reduzindo as preocupações a transmitância térmica e capacidade térmica de paredes externas, a transmitância térmica de coberturas e exigências limitadas de ventilação natural.

O aprimoramento das duas (2) normas, a partir dos textos vigentes é um segundo passo, a partir da reflexão, refinamento a atualização daquelas informações, ao qual em pequena parte este artigo pretende contribuir. 


\section{REFERÊNCIAS}

1. ASSOCIAÇÃO BRASILEIRA DE NORMAS TÉCNICAS. ABNT NBR 15575: Edifícios habitacionais Desempenho. Rio de Janeiro, 2013.

2. ABNT NBR 15220-3: Desempenho térmico de edificações - Parte 3: Zoneamento bioclimático brasileiro e diretrizes construtivas para habitações unifamiliares de interesse social. Rio de Janeiro, 2005

3. BOGO, Amilcar J. Limitações quanto aos parâmetros de desempenho térmico e estratégias bioclimáticas recomendadas pela norma brasileira de desempenho térmico de habitações de interesse social. Anais do NUTAU 2008 - 7o Seminário Internacional: Espaço Sustentável, São Paulo SP. São Paulo SP: NUTAU-USP, 2008.

4. BRITO, A. C. et al. Contribuições Para o Aprimoramento da NBR 15575 Referente ao Método Simplificado de Avaliação de Desempenho Térmico de Edifícios. Anais do Encontro Nacional de Tecnologia do Ambiente Construído, v. 14, 2012.

5. BRUAND, Yves. Arquitetura contemporânea no Brasil. 3a edição. São Paulo: Perspectiva, 1999.

6. D'ELL SANTO, Amabelli; ALVAREZ, Cristina Engel; NICO-RODRIGUES, Edna Aparecida. Conforto e desempenho térmico em contradição na NBR 15575. Cadernos do PROARQ 20. Rio de Janeiro Universidade Federal do Rio de Janeiro, Faculdade de Arquitetura e Urbanismo, Programa de Pós-Graduação em Arquitetura, julho, 2013.

7. GIVONI. B. Comfort, climate analysis and building design guidelines. Energy and Building. Vol.1, pp. 11-23, 1992.

8. MAHONEY, C. Climate and house design. Department of economic and social affairs. New York. United Nations, 93 p, 1971.

9. OLIVEIRA, Raquel Diniz; SOUZA, RVG; SILVA, R. M. Desempenho Térmico: qual valor devemos atender para a legislação brasileira? Anais do ENCONTRO NACIONAL DE CONFORTO NO AMBIENTE CONSTRUÍDO, v. 12, 2013.

10. RORIZ, Maurício e BASSO, Admir. Arquitrop: Conforto Térmico e Economia de Energia nas Edificações. Versão 3. 0 . São Carlos, 1995.

11. RORIZ, Maurício; GHISI, Enedir; LAMBERTS, Roberto. Uma proposta de norma técnica brasileira sobre desempenho térmico de habitações populares. Anais do ENCONTRO LATINO AMERICANO DE CONFORTO NO AMBIENTE CONSTRUÍDO, Fortaleza: ANTAC, 1999.

12. SORGATO, M. J.; MELO, A. P.; LAMBERTS, R. Análise do método de simulação de desempenho térmico da Norma NBR 15.575. Paranoá, Brasília, no 12, p. 13-22, 2014. 